\author{
UM TAPINHA NÃO DÓI: \\ um estudo da violência de gênero \\ Marilei Resmini Grantham*
}

\begin{abstract}
Along the years, many women have been suffering of violence without denouncing it for many reasons and mainly because of the involvement of preconception, discrimination and fear. The lack of these denounces, however, has been contributing for the construction of the social idea of insignificance of the act as well ridicularize these women. The dictates " all women like to be beaten" and " a love slap doen't hurt" been repeated along the times and represent the consolidation of this present situation. In this study I have the idea, therefore, to analyze and go thoughtful the discourse of/about the domestic violence against women. With this sense, I propose to analyze the circulation of this discourse in the different language materialization through music, internet researches and located in truck buffers in the way to observe the relation of these discourse in all built elements on author, text, another texts, interdiscourse, repetition and interpretation.
\end{abstract}

Resumo: Ao longo dos tempos, muitas mulheres têm sofrido violência, mas não denunciam a agressão por diversos motivos, os quais, geralmente, envolvem questões como preconceito, discriminação, medo. A falta de denúncia, no entanto, tem contribuído para a construção de um imaginário social que atenua a violência e ridiculariza a mulher. Neste contexto, enunciados como "toda mulher gosta de apanhar" e "tapinha de amor não dói", vêm sendo repetidos e representam uma forma de sedimentação desse sentido. Neste trabalho, pretendo tomar então, como objeto de análise e reflexão, o discurso da/sobre a violência doméstica praticada contra as mulheres. Com tal propósito, proponho-me a analisar a circulação desse discurso em diferentes materialidades lingüísticas - letras de música, depoimentos colhidos na Internet, frases escritas em pára-choques de caminhões - de modo a poder observar a relação desse discurso com todos os elementos que compõem o processo da produção de sentidos: autor, texto, outros textos, contexto, interdiscurso, repetição, interpretação.

\title{
INTRODUÇÃO
}

Este trabalho tem como objetivo refletir sobre o discurso da violência doméstica e sua relação com o gênero, tomando como referência o discurso sobre a violência contra a mulher.

Tomo a noção de gênero, aqui, como o conjunto de valores e informações biológicas, culturais e religiosas que ajudam a conformar a identidade, seja feminina ou masculina. Esses valores são reproduzidos ou moldados pela educação que os indivíduos recebem na família, na escola, na igreja, na sociedade.

A Convenção Interamericana para Prevenir, Punir e Erradicar a Violência Contra a Mulher, promovida em 1994, pela Organização dos Estados Americanos, definiu a violência contra a mulher como sendo "qualquer ato ou conduta baseada no gênero, que cause morte, dano ou sofrimento físico, sexual ou psicológico à mulher, tanto na esfera pública como na esfera privada”. Um ano antes, a ONU já havia reconhecido

\footnotetext{
* Docente do Curso de Letras da Fundação Universidade de Rio Grande.
} 
formalmente que a agressão contra mulheres era uma violação dos direitos humanos, constituindo um verdadeiro e gravíssimo problema de saúde pública.

Refletir sobre a forma de circulação desses sentidos sobre a mulher é um dos objetivos desse trabalho.

Com tal objetivo, inicio a discussão focalizando minha atenção na lei número 11.340 - a Lei Maria da Penha - decretada pelo Congresso Nacional e sancionada pelo presidente do Brasil Luiz Inácio Lula da Silva, em 7 de agosto de 2006.

\section{A LEI MARIA DA PENHA}

A lei leva o nome da biofarmacêutica Maria da Penha Maia, mulher que foi casada com o professor universitário Marco Antonio Herredia, o qual, em 1983, tentou matá-la duas vezes. Na primeira vez, deu um tiro e ela ficou paraplégica. Na segunda, tentou eletrocutá-la. Na ocasião, ela tinha 38 anos e três filhas, entre 6 e 2 anos de idade.

A investigação começou em junho do mesmo ano, mas a denúncia só foi apresentada ao Ministério Público Estadual em setembro de 1984. Oito anos depois, Herredia foi condenado a oito anos de prisão, mas usou de recursos jurídicos para protelar o cumprimento da pena.

O caso chegou à Comissão Interamericana dos Direitos Humanos da Organização dos Estados Americanos (OEA), que acatou, pela primeira vez, a denúncia de um crime de violência doméstica. Herredia foi preso em 28 de outubro de 2002 e cumpriu dois anos de prisão. Hoje, está em liberdade.

Após as tentativas de homicídio, Maria da Penha Maia começou a atuar em movimentos sociais contra violência e impunidade e hoje é coordenadora de Estudos, Pesquisas e Publicações da Associação de Parentes e Amigos de Vítimas de Violência (APAVV) no seu estado, o Ceará.

A Lei ${ }^{1}$ Maria da Penha entrou em vigor no dia 22 de setembro de 2006 e cria mecanismos para coibir a violência doméstica e familiar contra a mulher, nos termos do $\S 80$ do art. 226 da Constituição Federal, da "Convenção sobre a eliminação de todas as formas de discriminação contra as mulheres" e da "Convenção Interamericana para prevenir, punir e erradicar a violência contra a mulher"; dispõe sobre a criação dos "Juizados de violência doméstica e familiar contra a mulher"; altera o Código de Processo Penal, o Código Penal e a Lei de Execução Penal.

Neste estudo, tomamos como referência um pequeno livro distribuído pela Secretaria Especial de Políticas para as Mulheres, da Presidência da República, no qual encontramos, na introdução, um texto escrito por Nilcéa Freire - Ministra da Secretaria Especial de Políticas para as Mulheres - cujo título é o seguinte:

"É LEI! É PRA VALER!"

A materialidade lingüística deste enunciado produz vários sentidos, entre os quais o de que a lei está em vigor, o de que antes o controle da violência não era "pra valer”, o de que, sendo lei, vai realmente coibir a violência contra a mulher. Este enunciado, estampado no texto de introdução da lei, marca a inscrição deste discurso em uma FD que repudia a violência contra a mulher.

Tal posição é firmada pela referência a slogans que, segundo a ministra, "foram utilizados nas campanhas que trouxeram para o espaço público aquilo que se teimava

\footnotetext{
${ }^{1}$ Lei (do verbo latino ligare, que significa "aquilo que liga", ou legere, que significa "aquilo que se lê") é uma norma ou conjunto de normas jurídicas criadas através dos processos próprios do ato normativo e estabelecidas pelas autoridades competentes para o efeito.
} 
em dizer que deveria ser resolvido entre as quatro paredes do lar”. Os slogans referidos são: "Quem ama não mata”; "Em briga de marido e mulher, vamos meter a colher"; "Homem que é homem não bate em mulher"; "Toda mulher tem direito a uma vida livre de violência”; "Onde tem violência todo mundo perde".

Na materialidade desse discurso, o slogan "Toda mulher tem direito a uma vida livre de violência” dialoga com outro enunciado que, na verdade, constitui um princípio básico, o de que "todos" os cidadãos têm direito a uma vida sem violência. Assim, esse discurso de "inclusão", ao "selecionar" a mulher, entre os seres dignos de serem preservados da violência, age, paradoxalmente, como um discurso de exclusão, aquele que distingue a mulher do resto dos seres humanos.

Já os slogans "Quem ama não mata" e "Homem que é homem não bate em mulher” são ditos populares, ou seja, são enunciados que surgem neste texto introdutório da lei, mas que já foram, no entanto, produzidos anteriormente, em outros discursos e sob outras condições.

De forma semelhante, a materialidade lingüística do slogan "Em briga de marido e mulher, vamos meter a colher” nos revela um provérbio que também faz parte do senso comum: "Em briga de marido e mulher, ninguém mete a colher". Observa-se aqui uma ressignificação do provérbio, uma oposição entre diferentes posições-sujeito e, nesse confronto, é a identificação com a primeira posição - vamos meter a colher - que inscreve esse discurso na FD com a qual se identifica a campanha que coíbe a violência contra a mulher.

Queremos, neste ponto, fazer referência aos termos ditado, rifão, provérbio, adágio, dito, os quais confundem-se no uso corrente, tendo todos eles o sentido de sentença moral. Alguns autores procuram distingui-los, utilizando critérios como a antigüidade ou o uso popular. Assim, por exemplo, o provérbio pode aparecer ligado à forma clássica, colhida nas obras dos antigos filósofos gregos e romanos, e o adágio ligado à tradição oral; da mesma forma, o rifão pode ser visto como o provérbio que anda na boca do povo, e o adágio como o provérbio antiquado. Nenhum dos critérios utilizados, entretanto, na distinção entre os termos, parece suficientemente eficaz.

Não é meu objetivo, neste texto, fazer a distinção entre esses termos. Por isso, tomo a reflexão de Grésillon e Maingueneau (1984) sobre os provérbios, pois acredito que ela possa ser estendida ao discurso em análise.

Para os autores, o provérbio é o discurso citado por excelência e, mais precisamente, um caso de polifonia, representando não o propósito de um outro específico, mas de todos os outros. Assim, o provérbio mistura a voz do locutor a todas as vozes que proferiram antes o mesmo provérbio.

Em seu estudo, os autores citam A. Berrendonner, para quem o provérbio é classificado entre os fenômenos de menção, ou seja, enunciações tênues sobre uma outra enunciação. Eles dizem então:

Pode-se assim falar de "enunciação eco", na medida em que o enunciador do provérbio dá sua asserção como uma imitação, o eco, a reprise de um número ilimitado de enunciações anteriores deste mesmo provérbio. (ibid, p. 114)

Nesta perspectiva, considerado como uma autoridade indiscutível, o provérbio se sustenta graças à sua estruturação. Enunciando um provérbio, o locutor maximiza a validade do seu dizer, o lugar além da diversidade e da relatividade das autoridades.

Assim, este discurso sobre a lei, que dialoga com esse outro discurso, já sedimentado por esses ditos populares, neste novo contexto, dá a eles, também, o 
estatuto de inquestionáveis e de verdades absolutas. E identifica-se com esta FD em que o que pode e deve ser dito é que a violência contra a mulher precisa ser combatida.

É contra todas as formas de violência, então, que a Lei Maria da Penha se insurge e, em seu texto original, encontramos:

$\operatorname{Sd} 1^{2}$ : Art. $2^{\circ}$ Toda mulher, independentemente de classe, raça, etnia, orientação sexual, renda, cultura, nível educacional, idade e religião, goza dos direitos fundamentais inerentes à pessoa humana, sendo-lhes asseguradas as oportunidades e facilidades para viver sem violência, preservar sua saúde física e mental e seu aperfeiçoamento moral, intelectual e social.

E, em outro artigo:

Sd 2: Art.3 ${ }^{\circ}$ Serão asseguradas às mulheres as condições para o exercício efetivo dos direitos à vida, à segurança, à saúde, à alimentação, à educação, à cultura, à moradia, ao acesso à justiça, ao esporte, ao lazer, ao trabalho, à cidadania, à liberdade, à dignidade, ao respeito e à convivência familiar e comunitária.

Estranha sociedade, esta, em que é preciso criar uma lei que lembre que a mulher é uma "pessoa humana”. De uma lei para resguardar, à mulher, as condições para o exercício dos direitos à vida, ao acesso à justiça...

Isso me leva a refletir um pouco sobre esse discurso da lei, que existe para impor regras que devem funcionar para todos a quem a lei se dirige. É, pelo senso comum, um discurso objetivo, que não é produzido para ser questionado nem interpretado. É um discurso para ser lido na sua literalidade.

Doce ilusão, esta! Sabemos que a objetividade não existe, uma vez que qualquer discurso - mesmo o jurídico - é produzido por sujeitos e para sujeitos que, sob determinadas condições de produção específicas - sociais, políticas, econômicas, religiosas... - o interpretam. A literalidade dos sentidos, nesta perspectiva, não existe.

Tanto que encontramos, em um site da Internet, discussões e posicionamentos sobre a Lei Maria da Penha.

Vejamos:

Sd3: A $2^{\text {a }}$ Turma Criminal do TJMS (Tribunal de Justiça de MS) decidiu que a lei federal Maria da Penha é inconstitucional porque fere a igualdade entre homens e mulheres. A lei aumenta a punição para agressões à mulher. A decisão só vale para o processo em que Paulino José da Silva, 44, é suspeito de agredir a mulher e a filha. Ele foi preso em flagrante pela PM em março, em Itaporã (325 km de Campo Grande). Somente o STF (Supremo Tribunal Federal) pode julgar que uma lei é inconstitucional. Em depoimento, Paulino disse que foi agredido, que se defendeu sem bater, mas admitiu já ter agredido a mulher. Ficou nove horas preso, pagou fiança e foi solto. "Imagine um senhor de 70 anos que se case com uma mulher de 25 anos peso-pesado em judô. Se ela agredir o marido, a Lei Maria da Penha não pode ser aplicada", disse o juiz de Itaporã, Bonifácio Hugo Rauschà, à Folha. ( http://pfdc.pgr.mpf.gov.br)

Sd4: Portanto, nem a obediência estrita ao preceito isonômico constitucional permite questionar a indispensabilidade da Lei $n$. 11.340/06, que cria mecanismos para coibir a violência doméstica. A Lei Maria da Penha veio atender

2 A noção de seqüência discursiva é encontrada em Courtine (1981:25): são "seqüências orais ou escritas de dimensão superior à frase" 
compromissos assumidos pelo Brasil ao subscrever tratados internacionais que impõem a edição de leis visando assegurar proteção à mulher. A violência doméstica é a chaga maior da nossa sociedade e berço de toda a violência que toma conta da nossa sociedade. Os filhos reproduzem as posturas que vivenciam no interior de seus lares. Assim demagógico, para não dizer cruel, é o questionamento que vem sendo feito sobre a constitucionalidade de uma lei afirmativa que tenta amenizar o desequilíbrio que ainda, e infelizmente, existe nas relações familiares, em decorrência de questões de ordem cultural. De todo descabido imaginar que, com a inserção constitucional do princípio isonômico, houve uma transformação mágica. É ingênuo acreditar que basta proclamar a igualdade para acabar com o desequilíbrio nas relações de gênero. Inconcebível pretender eliminar as diferenças tomando o modelo masculino como paradigma. Não ver que a Lei Maria da Penha consagra o princípio da igualdade é rasgar a Constituição Federal, é não conhecer os números da violência doméstica, é revelar indisfarçável discriminação contra a mulher, que não mais tem cabimento nos dias de hoje. (http://cynthiasemiramis.org)

Podemos observar que esses sujeitos, ao produzirem seus discursos, assumem posições-sujeito diferenciadas em relação à constitucionalidade da lei, ou sejam, interpretam esse discurso. E o fazem com base no mesmo princípio, que é o preceito isonômico constitucional, relativo à igualdade entre homens e mulheres.

Assim, na sd3, lemos que a lei Maria da Penha é inconstitucional porque fere a igualdade entre homens e mulheres. E na sd4, lemos que a Lei Maria da Penha consagra o princípio da igualdade. Desta forma, embora ambos os discursos inscrevam-se na mesma FD, contra a violência, revelam posições opostas em relação à validade e à constitucionalidade da lei.

É interessante observar ainda que a palavra “igualdade” ganha sentidos diferentes nas duas seqüências discursivas.

Na sd3, temos: “... fere a igualdade. Aumenta a punição para agressões à mulher.” A igualdade, então, não é vista como o fato de ambos - homem e mulher deverem ter resguardado o seu direito de não sofrerem a violência, mas é concebida como um benefício para assegurar ao homem - e apenas ao homem - o direito de não ter aumentada a sua pena quando agride uma mulher.

Já na sd4, temos: “a lei consagra a igualdade”. Aqui, o termo ganha o sentido de equilíbrio (ameniza o desequilíbrio), de equivalência de direitos (eliminar as diferenças).

Tais considerações nos levam a pensar em Pêcheux (1988:160), quando o autor afirma que o sentido de uma palavra, de uma expressão, não existe em si mesmo, em sua relação com a literalidade transparente do significante, mas se produz de acordo com as posições ideológicas colocadas em jogo no processo sócio-histórico em que as palavras e expressões são produzidas. É isso que explica o fato de que as palavras e expressões mudam de sentido de acordo com as posições sustentadas por aqueles que as empregam, ou seja, com referência às formações ideológicas de quem usa essas palavras e expressões.

A língua, segundo esta concepção, não é transparente nem o mundo diretamente apreensível. E isso explica o fato de que o sentido da palavra "igualdade" não exista em si mesmo, mas que receba sentido de acordo com quem a emprega e a partir de que formação discursiva.

Além dessa interpretação sobre a constitucionalidade ou não da lei, encontramos avaliações sobre a sua importância e objetivos, como vemos a seguir: 
Sd5: "A Lei 11.340, de 7 de agosto de 2006, foi promulgada com o objetivo manifesto de "coibir e prevenir a violência doméstica e familiar contra a mulher" (art. $1^{\circ}$ ). Finalidade louvável, sem dúvida, o que a tornou motivo de aclamação praticamente unânime da doutrina nacional. Porém, em uma situação dessas, vem logo à mente, a advertência de Nelson Rodrigues de que "a unanimidade é burra”, pois nos incita ao simples adesismo, sem uma reflexão crítica. Esse é o mesmo raciocínio utilizado em diversas leis que visam proteger os "direitos das minorias", como o Estatuto do Índio (Lei 6.001/1973); a lei dos crimes de preconceito (Lei 7.716/1989); o Estatuto da Criança e do Adolescente (Lei 8.069/1990); e o Estatuto do Idoso (Lei 10.741/2003). A pretexto de combater a discriminação, criam-se novas diferenciações, em flagrante desrespeito ao princípio da igualdade que, ressalte-se, só pode ser excepcionado pela própria Constituição. Alexandre Magno Fernandes Moreira. Disponível em http://www.direitonet.com.br

Sabemos que, ao assumir a palavra, retomamos dizeres, mexendo na rede de filiação dos sentidos. Ao fazer isso, criamos uma espécie de jogo entre aquilo que já foi dito e aquilo que temos a dizer e é nesse jogo que os sentidos se sedimentam, se solidificam. Ou, por outro lado, se movimentam, re-significam.

Em Orlandi (1999), encontramos então:

Os processos parafrásticos são aqueles pelos quais em todo dizer há sempre algo que se mantém, isto é, o dizível, a memória. A paráfrase representa assim o retorno aos mesmos espaços do dizer. Produzem-se diferentes formulações do mesmo dizer sedimentado. A paráfrase está do lado da estabilização.” (ORLANDI, op. cit., p.36).

Desse modo, na sd5, esse sujeito produz um dizer dividido, entermediado pela conjunção mas, entre uma posição favorável à lei (finalidade louvável) e uma posição contrária (adesismo, sem reflexão crítica).

No entanto, note-se que, ao fazer ressoar, nas suas palavras, outras palavras, as de Nelson Rodrigues - "toda unanimidade é burra" - ele marca sua identificação com tais palavras e sua posição contra a Lei Maria da Penha.

Esse discurso da violência de gênero, sabemos, circula na sociedade, através de diferentes materialidades linguisticas, e não apenas através dessa lei. É sobre isso que passamos a discorrer a seguir.

\section{OUTRAS MATERIALIDADES LINGÜÍSTICAS}

Podemos encontrar esse discurso, por exemplo, em pára-choques de caminhões:

Mulher feia, cachorro e cobra, comigo é na paulada.

Mulher é como bife, só amacia quando apanha.

Mulher feia e urubu comigo é na pedrada.

Mulher é como índio, se pinta quando quer briga.

Enunciados como estes constroem o imaginário social da mulher em que ela é comparada aos animais (cachorro, cobra, urubu), é ridicularizada (se pinta quando quer briga) e vista como coisa (bife). Coisa para ser consumida, degustada - mas depois de apanhar.

Esse sentido de brincadeira em relação à violência está presente também na materialidade linguistica de músicas. 


\begin{tabular}{|l|l|}
\hline Um Tapinha Não Doi & Tapa Na Cara \\
Furacão 2000 & Pagodart \\
Vai Glamurosa & Se ela me pedir...o que vou fazer... \\
Cruze os braços no ombrinho & Meu deus me ajude em mulher não vou \\
Lança ele prá frente & bater \\
E desce bem devagarinho... & Mas ela me pede todo dia toda hora \\
Dá uma quebradinha & quando a gente faz amor \\
E sobe devagar & Pedi o quê? \\
Se te bota maluquinha & Se ela me pedir...o que vou fazer... \\
Um tapinha eu vou te dar & Meu deus me ajude em mulher não vou \\
Porque: & bater \\
Dói, um tapinha não dói & Mas ela me pede todo dia toda hora \\
Um tapinha não dói & quando a gente faaaaaaazamooooor \\
Um tapinha não dói & Tá tá tapa na cara, tapa na cara \\
Só um tapinha....(2x) & Tapa na cara, tapa na cara \\
& Tapa na cara mamãe, tapa na cara \\
& Na cara mamãe \\
& Se você quiser, ai eu vou te dar \\
& \\
\hline
\end{tabular}

É fácil observar, nas letras dessas músicas, a construção do discurso que tem sido denominado, em nossa sociedade, como "machista" ${ }^{3}$ e que pode ser pensado como um discurso que inferioriza a mulher ou ridiculariza-a.

Assim, nessas músicas, vemos a violência ser associada ao prazer sexual, e produz-se a imagem de uma mulher que pede para apanhar porque isso a deixa maluquinha e que pede tapa na cara quando faz amor.

$\mathrm{Na}$ construção desse discurso, a violência é disfarçada e amenizada pelo uso de adjetivos como glamurosa e pelo emprego de diminutivos como ombrinho, tapinha, que revestem os gestos de agressão de meiguice e carinho. Note-se ainda, em construções como "Se ela me pedir.. o que vou fazer?" e "Meu Deus, em ajude, em mulher não vou bater, mas ela me pede todo dia...", "Se você quiser, aí eu vou te dar...", que a violência deixa de ser considerada uma responsabilidade do agressor e passa a ser uma responsabilidade da mulher agredida: é ela quem pede, é ela quem quer, é ela quem gosta; não há culpa, portanto, da parte de quem bate.

Esse discurso jocoso acaba por chancelar a violência do homem contra a mulher e, cantado em paradas musicais, passa a ser repetido, a ser tomado como "normal" e a esconder uma certa conivência da sociedade para com a violência doméstica.

Na busca por entender melhor esse discurso da violência de gênero, analiso ainda alguns depoimentos retirados de um site da Internet, no qual se criou um fórum a partir da seguinte pergunta: "Mulher gosta de apanhar"?

Tomo, como ponto de partida, a resposta de um homem $(\mathrm{H})$, a partir da qual se desenrola a discussão:

\footnotetext{
${ }^{3}$ Em países católicos como a Espanha, Itália, Portugal e em toda a América Latina, Machismo ou chauvinismo masculino é a crença de que os homens são superiores às mulheres. O machismo não é algo recente. Ele possui raízes que provém da antiga cultura greco-romana.Na época de sua origem,era pouco questionado pelas mulheres,pois as mesmas eram privadas de acesso ao conhecimento e aos estudos,logo não refletiam acerca de sua condição e pouco faziam.A partir da metade do século XX,as mulheres passaram a ter um maior acesso ao conhecimento e aos estudos,inclusive de filosofia.A partir desse maior acesso,as mulheres passaram a reivindicar os seus direitos,e uniram-se e agora buscam seus direitos tanto em casa como no mercado de trabalho. Alguns casos em que ocorre o machismo: infidelidade, violência domestica, diferença de direitos, esporte. (http://teoriadomachismo.blogspot.com)
} 
H / Sd6: "Dar uns tapinhas na hora certa não se constitui em violência e não é crime. Entre quatro paredes tudo vale entre um homem e uma mulher desde, é claro, que haja consentimento de ambas as partes. Como diria Nelson Rodrigues: "Nem todas as mulheres gostam de apanhar. Só as normais."

Podemos reconhecer, aqui, uma relação de paráfrase entre o dizer desse sujeito e o sentido produzido pelo discurso da violência revestido de deboche que verificamos nas letras das músicas: neste discurso, num efeito da memória discursiva, o dizível se mantém e sedimenta o sentido de que a violência é associada ao sexo, ao prazer, à diversão.

Mais uma vez, vemos o sujeito-autor validar seu discurso pelo atravessamento de um outro discurso, o de Nelson Rodrigues, quando este dizia: "Nem todas as mulheres gostam de apanhar. Só as normais." Observe-se que, neste enunciado, o jogo entre as expressões restritivas nem todas $\mathrm{x}$ só as normais produz 0 efeito de sentido de que é normal a mulher gostar de apanhar. Repetir o sentido (re)produzido por Nelson Gonçalves é então a forma de este sujeito identificar-se com esse sentido e com essa formação discursiva na qual o que pode e deve ser dito é que a violência contra a mulher é normal.

Vejamos então a posição assumida pelas mulheres (M), ao dialogarem com essa pergunta e com a resposta dada por esse sujeito.

M1/ Sd7: "Essa teoria de que mulher gosta de apanhar é coisa de homem covarde que não assume as suas responsabilidades e com isso desconta em cima de mulheres que na maioria das vezes dependem deles economicamente ou apenas emocionalmente (muitas tem filhos com os agressores) e por isso temem que se os denunciar ou abandonar seus filhos possam ser atingidos pela fúria desses agressores que as ameaçam e a seus filhos. Meu conselho é para que mulheres e famíliares denunciem esses covardes, pois é cadeia que eles merecem.”

M2/ Sd8: "Não estamos falando de fantasia sexual. Estamos falando de violência. Não acredito que exista uma única mulher que goste de ser agredida, mas deve ser uma situação muito complicada. O agressor, normalmente, é o pai dos filhos da mulher; estão juntos há anos, o que significa que em algum momento, se amaram; vergonha de se expor; impunidade - o agressor vai à delegacia prestar depoimentos, passa uma noite e volta para casa. São alguns dos motivos que podem fazer com que a mulher fique calada. Eu tenho uma amiga que em uma briga louca com o marido, tomou um tapa dele (e olha que ela também bateu nele). Ela não teve dúvidas, foi na delegacia das mulheres. Nunca mais ele encostou um dedinho nela - não para agredir...

M3/ Sd9: "Muitas não tomam atitude por medo. Outras até gostam porque são sem vergonha mesmo."

M4/ Sd10: "Acredito que sim mas nao daqueles jeitos brutais talvez uma coisa mais amena mas muitos homens acreditam que todas mulheres gostam de apanhar o que nao é o caso."

M5/ Sd11: "Olha só,eu detesto homens violentos... Mas, meu irmão,se apaixonou por uma mulher,q pedia pra apanhar, rss... Ele,me perguntou o q fazer...eu disse: dê nela pião...até ela pedir pra parar, rssss. Fazer o q, se tem mulheres q gostam, não são resolvidas diante da sociedade e das famílias?!!!........ Dpois, quando as outras, q como eu não gostam (mas,fico na minha,rss) falam, elas dizem q o cara é qé um animal?!!!! Vá entender!!!!!!!!!!!!!!

A análise desse discurso nos leva a fazer referência a Pêcheux (1969:77), quando o autor afirma que o processo discursivo não tem, de direito, início, pois o discurso se conjuga sempre sobre um discurso prévio. 
Deste modo, segundo Pêcheux (1988:261), "um efeito de sentido não preexiste à formação discursiva na qual se constitui”, sendo a produção de sentido parte integrante da interpelação do indivíduo em sujeito, já que este é produzido na forma-sujeito do discurso, sob o efeito do interdiscurso.

Podemos perceber, assim, na fala dessas mulheres, sujeitos enunciadores desse discurso, diferentes formas de relação com o sujeito de saber da FD em que o que pode e deve ser dito é que a violência contra a mulher é uma agressão inadmissível.

Sabemos que "nossas” palavras nunca são só nossas, que elas significam pela história e pela língua, e que o que é dito em outro lugar também nelas significa. Assim, o fato de que existe um já-dito sustenta a possibilidade mesma de todo dizer e é fundamental para que possamos compreender o funcionamento do discurso, sua relação com os sujeitos e com a ideologia.

Tais considerações nos remetem à noção de memória discursiva, noção trazida para a AD por Courtine (1981), que a trata não dentro de uma concepção individual de um inconsciente coletivo, mas como memória social inscrita no seio das práticas discursivas.

A memória social, como ressalta Mariani (1998) é

..um processo histórico resultante de uma disputa de interpretações para os acontecimentos presentes ou já ocorridos, sendo que, como resultado do processo, ocorre a predominância de uma de tais interpretações e um (às vezes aparente) esquecimento dos demais. (Mariani, 1998:34)

Podemos dizer que esse discurso está submetido inconscientemente a uma memória social que o conduz a um determinado movimento de interpretação, que, por sua vez, estabelece a predominância de um sentido - o de que as mulheres gostam de apanhar - em detrimento de outros.

Nesse discurso, temos, então, por um lado, uma posição-sujeito de repúdio àquela assumida por $(\mathrm{H})$ e que pode ser verificado em marcas lingüísticas (pistas da construção de sentidos) que se referem aos homens com palavras como covarde (M1), agressores (M1), fúria (M1), ameaçam (M1), cadeia (M1), violência (M2), impunidade (M2). E que caracterizam a mulher através de termos como vergonha (M2), medo (M3).

Temos também a reprodução do sentido criado tanto pela expressão "toda mulher gosta de apanhar" (que deu origem à pergunta) quanto pela resposta de $(\mathrm{H})$. Esse efeito de mesmo pode ser percebido em "Acredito que sim..."(M4), em "Outras até gostam..." (M4)ou em "Fazer o q, se tem mulheres q gostam..." (M5).

Sabemos ainda que, em $\mathrm{AD}$, é a noção de posição-sujeito que designa a relação de identificação entre sujeito enunciador e sujeito do saber da $\mathrm{FD}^{4}$, o que explica o fato de que diferentes sujeitos, relacionando-se com o sujeito do saber de uma mesma FD, possam assumir diferentes posições-sujeito, produzindo diferentes efeitos-sujeitos em seu discurso. E é isso também que nos permite dizer que o discurso é, constitutivamente, heterogêneo, ou seja, que o discurso abriga tanto o contato entre diferentes formações discursivas e suas respectivas formas-sujeito, quanto o contato entre diferentes posições-sujeito que se inscrevem em uma mesma formação discursiva.

\footnotetext{
${ }^{4}$ É a forma pela qual o sujeito do discurso identifica-se com a formação discursiva que o constitui. Esta identificação baseia-se no fato de que os elementos do interdiscurso, ao serem retomados pelo sujeito do discurso, acabam por determiná-lo. Também chamado de forma-sujeito ou sujeito universal, é responsável pela ilusão de unidade do sujeito.
} 
Em outras palavras: no discurso, o mesmo convive com a diferença e com a divergência, criando espaço para a contradição.

É esta heterogeneidade, esta convivência entre o que está instituído e o que procura se instituir que notamos também neste discurso, em enunciados como:

"Acredito que sim, mas não daqueles jeitos brutais talvez uma coisa mais amena" (M4).

Neste discurso, o senso comum aparece na primeira parte do enunciado Acredito que sim - e remete para a FD (FDX) onde o formulável é mulher gosta de apanhar, mesmo que de uma forma mais amena. Já na segunda parte, o dizer remete para outra FD (FDY), na qual o formulável é mulher não gosta de apanhar de jeito brutal.

Ou ainda em:

“Olha só, eu detesto homens violentos... Mas, meu irmão se apaixonou por uma mulher, q pedia pra apanhar..." (M5)

Neste caso, a primeira parte do enunciado - Olha só, eu detesto homens violentos - é que remete para a FDY, enquanto a outra parte - Mas, meu irmão se apaixonou por uma mulher, q pedia pra apanhar - remete para a FDX, onde o formulável é mulher gosta de apanhar.

O que temos aqui são enunciados divididos, que revelam um discurso atravessado por dizeres que se identificam com formações discursivas que se opõem.

O que podemos perceber, então, são diferentes formas de relacionamento dos sujeitos com o sentido instituído em relação à violência contra a mulher.

\section{CONCLUINDO}

Para finalizar, deixo, neste trabalho que pretendeu examinar o discurso sobre a violência de gênero, uma imagem de um outdoor, para reflexão:

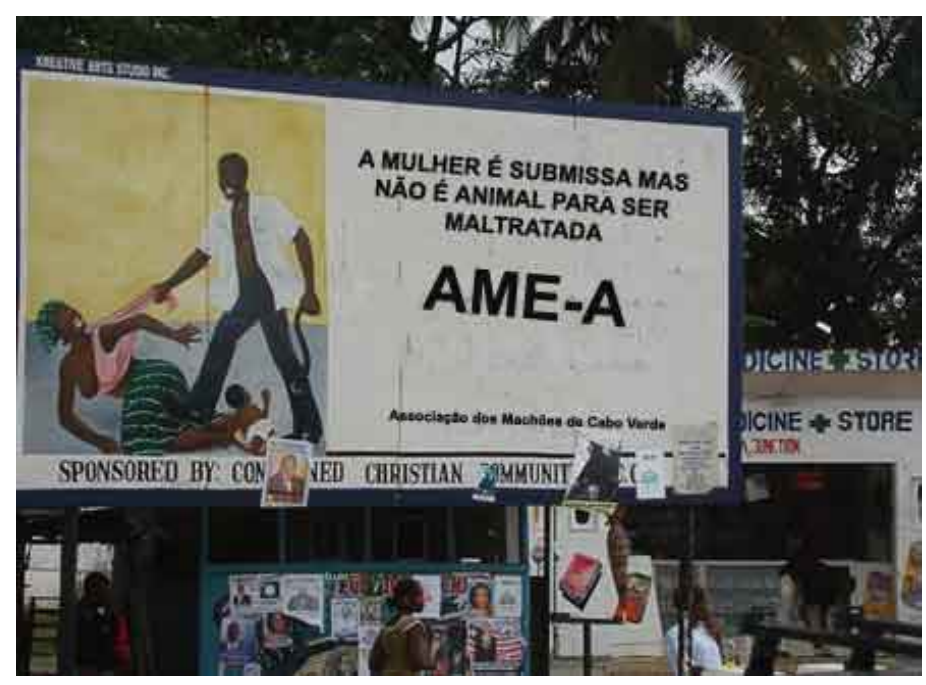

Na materialidade lingüística desse enunciado, vemos: “A mulher é submissa, mas não é animal para ser maltratada. Ame-a."

Ressalto, então, o Art. 5º da Lei Maria da Penha:

Art. $5^{\circ}$ Para os efeitos desta Lei, configura violência doméstica e familiar contra a mulher qualquer ação ou omissão baseada no gênero que lhe causa morte, lesão, sofrimento físico, sexual ou psicológico e dano moral ou patrimonial. 
Neste discurso, que se constrói como “defensor” de uma causa contra a violência à mulher, os sentidos escapam, sem controle de quem o enuncia, e vários sentidos se produzem: o de que a mulher é inferior (e o homem é superior, o que pode ser visto pela imagem), que o homem domina a mulher (e por isso ela é submissa, e pode ser subjugada, agredida), que animais são inferiores (e podem ser maltratados), que as mulheres podem ser comparadas aos animais (senão, isso não precisaria ser dito) e que é preciso "lembrar" às pessoas que as mulheres devem ser amadas.

Assim, podemos perceber que, sob diferentes formas, o discurso da violência, embora camuflado, acaba sempre retornando e sedimentando-se. Infelizmente!

E, hoje, casos de violência de mulheres contra homens também passam a ser comuns. Vejamos o depoimento de um homem, também em um site da Internet:

"Ficaria meio estranho um homem ir à delegacia para dizer que a mulher bate nele. É vergonhoso demais, pegaria mal". Receio de apanhar, contudo, ele diz que nunca teve - e se orgulha disso. "Nunca me senti intimidado porque ela é mais fraca. Eu me defendia segurando os braços dela, puxando o cabelo para trás. Ela nunca chegou a me machucar", garante.

Neste discurso, podemos reconhecer as mesmas palavras que encontramos no discurso feminino sobre a violência, o que nos permite lembrar que o discurso, sendo efeito de sentido entre interlocutores, nasce sempre a partir de determinadas condições de produção - sociais, históricas, políticas. Assim, em tempos de emancipação feminina, é possível que este discurso da violência esteja mudando? Ou sempre existiu, sem ser dito?

Mas isso é assunto para um outro texto...

\section{REFERÊNCIAS}

COURTINE, Jean Jacques. Analyse du discours politique. Langages. Paris, Larousse, v.62, p. 0-128, 1981.

MARIANI, Bethania. O PCB e a imprensa; os comunistas no imaginário dos jornais (1922-1989). Campinas: Editora da Unicamp, Rio de Janeiro: Revan, 1998.

ORLANDI, Eni. Análise de Discurso: princípios e procedimentos. Campinas, São Paulo, 1999.

PÊCHEUX, Michel. Semântica e Discurso: uma crítica à afirmação do óbvio. Campinas: Ed. Unicamp, 1988. 